\title{
Los trabajadores del Ferrocarril de Tehuantepec y la huelga "olvidada" de Rincón Antonio (1903)
}

\author{
The Tehuantepec Railroad Workers and the \\ "Forgotten" Strike of Rincon Antonio (1903)
}

\author{
Mauricio Sedano Ortega \\ Posgrado en Historia \\ Universidad Nacional Autónoma de México, México | onadesagetro@gmail.com
}

\begin{abstract}
Resumen
En este artículo pretendemos, a partir de fuentes principales como son los telegramas enviados durante el conflicto, demostrar que la huelga de trabajadores de Rincón Antonio -pequeña población oaxaqueña del Istmo-fue uno de las primeras acciones de inconformidad contra las políticas laborales de principio del siglo xx en México. Para lograr nuestro objetivo, analizaremos los espacios donde se desarrolló la huelga, los lugares donde laboraban los empleados y los sueldos que recibían, además de la participación de la Unión de Mecánicos Mexicanos.
\end{abstract}

Palabras clave: huelga; trabajadores; Unión de Mecánicos Mexicanos; talleres; ferrocarril.

\begin{abstract}
The aim of the paper is to define the workers' strike in Rincon Antonio, a small Oaxacan town on the Isthmus as one of the first movements against the early 20th century labor policies in Mexico. The paper describes the strike and its environment, working conditions and workplaces, workers' salaries and the participation of the Union of Mexican Mechanics.
\end{abstract}

Key words: strike; workers; Mexican Mechanics' Union; workshops; railroad.

Fecha de recepción: 3 de marzo de 2014 Fecha de aceptación: 28 de abril de 2015 


\title{
Los trabajadores del Ferrocarril de Tehuantepec y la huelga "olvidada" de Rincón Antonio (1903)
}

\author{
Mauricio Sedano Ortega
}

No estoy seguro de que se pueda cambiar el destino, pero sí creo que debemos hacer todo lo que esté a nuestro alcance para cambiar las cosas que no nos gustan [...] Aquella noche no nos quedamos esperando que pasara el tren, lo pusimos en marcha.

Próxima salida $(2004)^{*}$

$\mathrm{D}$ urante los 30 años que gobernó Porfirio Díaz existieron diversos conflictos en distintos sectores de la sociedad que fueron solucionados por la política de "pan o palo". A finales del siglo xix hubo constantes huelgas de trabajadores tanto en las industrias como en los transportes que surgían por aquí y por allá, sin generar, según decían los portavoces del presidente Porfirio Díaz, más que unas cuantas "llamaradas de petate", nada que espantara al gobierno. A principios del siglo xx las cosas cambiarían y el cúmulo de experiencias de los trabajadores crecería. En 1903, una de esas movilizaciones fue la emprendida por los mecánicos de los talleres de Rincón Antonio, en Juchitán, Oaxaca, quienes decidieron irse a huelga en contra de la empresa del Ferrocarril del Istmo; la razón fue el aumento de las horas de trabajo y la disminución de los sueldos. Los trabajadores, para hacer más fuerte su lucha, pidieron el apoyo de la sucursal número 6 de la Unión de Mecánicos Mexicanos (la Unión), de los fogoneros de Coatzacoalcos y de otros empleados.

* "Aquella noche algo había pasado, algo que nos modificaría para siempre; algo que tenía que ver con la bronca, la injusticia, las leyes, los derechos, sobre todo con cada uno de nosotros, algo que tenía que ver con nuestra identidad, con ser parte de algo que nos perteneció siempre y no sé por qué creíamos ajeno e inalcanzable. Todavía me pregunto por qué mi viejo no vio una salida, yo estoy seguro que alguna debe haber y no voy a parar hasta encontrarla." Las dos citas fueron tomadas de una película argentina llamada Próxima salida, de Nicolás Tuozzo, 2004. Agradezco a la doctora Rosalina Ríos y al licenciado Cristian Rosas por la recomendación de esta película. 
¿Qué importancia tuvo esta huelga dentro del conjunto de los conflictos laborales sucedidos en este periodo histórico?, ¿qué resultados alcanzaron los trabajadores del Istmo?, ¿cuáles fueron las acciones y demandas de los trabajadores en la huelga?, ¿cuál fue la relevancia de la participación de la Unión de Mecánicos Mexicanos?, ¿cómo reaccionó la empresa del ferrocarril ante dichas acciones?

Armando Rojas (1995, 2004), quien se ha encargado de estudiar esa huelga de 1903, nos menciona que la importancia de dicho conflicto radica, por un lado, en el silencio por parte de la prensa, supeditada tanto al control que tenía el gobierno como la empresa ferrocarrilera Pearson and Son Limited (Pearson) ${ }^{1}$ y, por otro, como antecedente de las huelgas de Cananea y Río Blanco. Sumado a esto, la historiografía encargada de dar cuenta de los trabajadores y sus formas de organización menciona el valor del sector ferrocarrilero como uno de los primeros grupos que cambió de sociedad mutualista a sindicato, por ser uno de los sectores mejor estructurados y vinculados a la economía del momento; el cambio ejemplar para explicar este suceso ha sido la Unión, pues apoyó diversas huelgas a principios del siglo xx (Basurto, 1970; Clark, 1979; Leal, 1985, 1991; Shabot, 1982; Woldenberg, 1980, 1982). No obstante, estos autores siguen sin explicar y sin darle un lugar a las huelgas anteriores a 1906, como lo fue la de Rincón Antonio, debido a que se le ha juzgado únicamente a partir de los resultados y las consecuencias que se obtuvieron; en el caso de Rojas, simple y llanamente se concreta a presentar los telegramas sin analizar a profundidad su contenido.

El presente artículo mostrará que el conflicto surgido en los talleres de Rincón Antonio fue una muestra clara de los primeros intentos de los trabajadores por "alzar la voz" y demostrar su descontento ante la situación laboral a inicios de 1900, debido a los límites alcanzados por el régimen de Porfirio Díaz. Ese "alzar la voz" de estos trabajadores sirvió no sólo para pedir mayores sueldos y reducción de la jornada de trabajo, sino también posibilitó

${ }^{1}$ La empresa Pearson and Son Limited fue una de las mayores y principales compañías británicas alrededor del mundo. Entre 1880 y 1920 cumplió más de ochenta contratos de obras públicas en el plano internacional, desde proyectos de drenaje y aguas negras hasta prestigiosos proyectos de ingenierí, incluyendo ferrocarriles y obras portuarias. En México realizó el Gran Canal del Desagüe en el Valle de México, las obras portuarias de Veracruz, Salina Cruz y Coatzacoalcos, así como el Ferrocarril Nacional de Tehuantepec. Es claro que, en el caso de México, sacó grandes ventajas económicas, varios metros cuadrados de tierra y una empresa petrolera llamada El Águila. Garner (2005).

\section{(이요}


actuar en conjunto con otros sectores del ramo y buscar contratos que fueran colectivos, no sólo individuales, como se usaba en la época.

Se utilizó como fuente principal el documento Huelga de maquinistas, empleados y fogoneros, ubicado en el Archivo General de la Nación. El expediente contiene catorce telegramas ${ }^{2}$ donde los trabajadores, los empleados de la empresa y las autoridades políticas estatales intercambiaron comunicación con Leandro Fernández, secretario de Comunicaciones y Obras Públicas, sobre cómo avanzaba la situación de la huelga. ${ }^{3}$ En estos documentos nos fue posible identificar la voz de los trabajadores en huelga. Además, utilizamos otros documentos y bibliografía sobre el tema.

El artículo, organizado en cuatro partes, primero expone cómo se desarrolló la huelga y los argumentos que dieron los participantes. En seguida, los escenarios donde tuvo lugar: Rincón Antonio y Coatzacoalcos. Luego se abunda sobre el trabajo de los mecánicos y fogoneros en la empresa Pearson. Finalmente, introduce la historia de la Unión de Mecánicos Mexicanos para comprender la función de dicha agrupación en la huelga; así explicaremos de forma tangible qué fue la huelga de 1903, a sus actores y sus resultados.

\section{LA HUELGA DE 1903}

Los mecánicos de Rincón Antonio mandaron un telegrama a Leandro Fernández, secretario de Comunicaciones y Obras Públicas, el 15 de abril de 1903. En él le comunicaban que se lanzaban a huelga porque estaban en contra del aumento de horas y la reducción de sueldos que había aprobado la compañía Pearson and Son Limited, encargada de construir el Ferrocarril de Tehuantepec. Las exigencias de los trabajadores eran claras, y las enunciaban así:

1ra. Que a todos se les den sus respectivos trabajos y que al separar cualquiera será con causa justificadas. 2a. Se trabajaran las 59 horas a la semana como de costumbre y los domingos las 8 horas. 3a. Harán un aumento sobre el sueldo de todos del 10\% para los de esta y 15\% en Rincón Antonio. 4a. Que todo in-

${ }^{2}$ El telegrama fue uno de los primeros medios de comunicación que buscó facilitar el intercambio de información entre las personas, pues se caracterizaba por ser un escrito breve; además, tenía la ventaja de que el destinatario podía recibirlo "en corto tiempo". La forma como inicialmente se transmitió fue a través del código Morse.

${ }^{3}$ Huelga de maquinistas, empleados y fogoneros. Abril 1903. Fondo Secretaría de Comunicaciones y Obras Públicas. 2/673-1. Archivo General de la Nación (AGN), México.

\section{()(1) $\$$}


dividuo que sea llamado a trabajar fuera de las horas ordinarias se les dará el $50 \%$ más sobre sueldo como ha sido costumbre. 5a. Los nocturnos trabajaran 15 horas y tendrá el $10 \%$ más al que ha sido costumbres hacerles. ${ }^{4}$

Destaca en estas líneas que los mecánicos mantenían una concepción en conjunto con los demás trabajadores que laboraban con ellos y no nada más con quienes compartían su oficio. Esta acción marca un cambio trascendental con respeto a otros conflictos laborales de la época, pues denota la unión de los trabajadores cuando mencionan que la huelga no sólo será de mecánicos sino que al movimiento se les unían los fogoneros y otros empleados. En el caso de los fogoneros de Coatzacoalcos, antes de que los trabajadores de los talleres de Rincón Antonio iniciaran su paro, se habían levantado en huelga en contra de la empresa Pearson. Al no llegar a un acuerdo con esta para que satisficiera "de manera honrosa sus necesidades", 5 decidieron no regresar al trabajo; en cambio, se sumaron a la huelga de Rincón Antonio. Sumado a ello, solicitaron y recibieron el apoyo de la sucursal número 6 de la Unión, cuyo presidente era Ramón Gallinar (el encargado de representar a los trabajadores ante las autoridades). Este entramado muestra la importancia que comenzaron a cobrar las uniones de trabajadores en el siglo pasado, cuando su apoyo rebasó la idea de ayuda mutua por una donde el uso de la huelga se convirtió en un arma de combate más directa a favor de los trabajadores (Leal, 1985, p. 50).

Los mecánicos también mencionaban en el telegrama que no estaban interesados en generar un problema en contra del ferrocarril ni de sus empleados, y, en caso de suceder algún accidente, se achacaría la responsabilidad a la persona que lo cometiera. Dicha situación nos "recuerda la estabilidad social" pregonada por el porfiriato, encubierta a partir de la política de "pan o palo"; sin embargo, es claro que los mecánicos dejan traslucir en sus palabras que la "paz porfiriana" no fue lograda sólo con diálogo.

Evidentemente las cosas no iban bien para los mecánicos y demás trabajadores, pues el 20 de abril solicitaron que Leandro Fernández fuera intermediario en el conflicto entre ellos y la empresa. Para esas fechas los problemas entre patrón y trabajador se resolvían entre ellos, no existía una

${ }^{4}$ Huelga de maquinistas, empleados y fogoneros. 15 de abril de 1903. Fondo Secretaría de Comunicaciones y Obras Públicas. 2/673-1. AGn, México.

${ }^{5}$ Huelga de maquinistas, empleados y fogoneros. 15 de abril de 1903. Fondo Secretaría de Comunicaciones y Obras Públicas. 2/673-1. Agn, México.

\section{(ㄷ)(1) $\$$}


legislación que lo regulara (Lear, 1997, p. 280); no está de más recordar que las leyes "obstaculizaron de manera efectiva la mayor parte de las huelgas y las actividades sindicales [de la segunda mitad del siglo xIX]" (Lear, 1997, p. 281).

Ese mismo 20 de abril, pero a las dos de la tarde, los mecánicos le informaban al secretario que la empresa les había pagado "el cincuenta por ciento de operarios día y hora de trabajo en pago", pero que habían sido incompletos los sueldos de los trabajadores y por ello le pedían instrucciones.

Los resultados siguieron siendo adversos para los mecánicos y sus compañeros. Informaban a Fernández que habían organizado una comisión para que se reuniera con él con el fin de exponerle "verbalmente de la situación y actitud de los huelguistas, así como las situaciones que obligan a lo futuro". ${ }^{6}$ Desafortunadamente, no sabemos si el secretario recibió a dicha comisión y cuál fue el arreglo al que llegaron, pues ese es el último telegrama que conocemos sobre el asunto de la huelga de 1903.

La empresa también le informaría a Leandro Fernández (scop) sobre la situación de la huelga. En uno de los telegramas, J. Glasgow (empleado de la empresa) informa el 20 de abril a John Body (representante de Pearson en México) sobre la situación de la huelga, diciéndole que el traslado que se había hecho de los talleres de Coatzacoalcos a Rincón Antonio había dado como consecuencia el despido de varios trabajadores, porque ya no serían utilizados sus servicios. Para el 28 de abril, Glasgow le comunicó a Emiliano Velasco (representante legal de la empresa) que no existió una huelga de empleados del ferrocarril, que no se había interrumpido el tráfico comercial en la vía férrea y los trabajos no se habían detenido: "lo que ocurrió fue que el personal del taller se declaró [en] huelga". Las contradicciones de Glasgow y de Emiliano nos indican el interés por proteger a la compañía y las labores que se realizaban en el ferrocarril, por eso se trató de desvirtuar el movimiento aseverando que no había tenido mayores consecuencias y los argumentos dados por los trabajadores no eran de gran relevancia para darle cauce a una huelga. Una de las medidas que se tomaron fue el despido de los huelguistas en aras de proteger el avance del proyecto: la línea del Ferrocarril del Istmo, que traería "el progreso".

${ }^{6}$ Huelga de maquinistas, empleados y fogoneros. 28 de abril de 1903. Fondo Secretaría de Comunicaciones y Obras Públicas. 2/673-1. Agn, México.

${ }^{7}$ Cabe recordar que la construcción del Ferrocarril Nacional de Tehuantepec fue para generar "un puente comercial mundial" y, a su vez, fue considerado una de las obras más importantes del régimen porfirista; de ahí la necesidad del gobierno y de la empresa de proteger la vía férrea frente a cualquier posible contratiempo que surgiera, más aun cuando para

\section{()(1) $\$$}


El gobernador de Oaxaca y los jefes políticos de Tehuantepec y Juchitán también dieron su informe a Leandro Fernández acerca de lo sucedido en los talleres de Rincón Antonio. Se limitaron a decir que tenían conocimiento del conflicto, que giraron instrucciones para que se ejerciera vigilancia y se evitara trastornar el orden público. Resulta curioso que las autoridades de Veracruz no presentaran un informe de la movilización en Coatzacoalcos. La calma en la que se encontraban las autoridades respecto a las movilizaciones era porque no cobraron relevancia alguna del 17 al 20 de abril.

La huelga duró catorce días y cada uno de los participantes emitió diferentes telegramas con los que pretendían argumentar, según sea el interlocutor, si existió o no ese movimiento, cuáles fueron las acciones que se realizaron para detenerlo, las causas y motivos de por qué se dio. Se puede notar en la huelga una lectura sobre las primeras acciones que realizaron los trabajadores con ayuda de las sociedades de resistencia, como lo fue la Unión en aquellos momentos, para defender sus derechos laborales, a partir de la alianza de diferentes sectores de trabajadores -mecánicos, fogoneros y empleados del ferrocarril-, frente al avance político y económico de las empresas que los estaban afectando de manera directa.

\section{LOS ESCENARIOS: RINCÓN ANTONIO Y COATZACOALCOS}

La huelga surgió en dos puntos estratégicos de la vía del istmo: Rincón Antonio y Coatzacoalcos. El primero albergaba los talleres de mantenimiento de las locomotoras, por ser la estación justo a la mitad de todo el trayecto; en el segundo se encontraban las oficinas principales de la vía, y era el punto de entrada y salida del comercio marítimo. Importa decir que no tenemos conocimiento de que la huelga se extendiera a otro punto del ferrocarril, como Salina Cruz o Minatitlán, que fueron ciudades importantes del istmo, al contrario, nos parece sospechoso que no sucediera así, pese a la relevancia de estos lugares.

Rincón Antonio, ubicado en Juchitán, Oaxaca, era una ranchería más de la zona hasta que en 1902 empezó a urbanizarse por la construcción de

1903 apenas se llevaban cuatro años de trabajo bajo las órdenes de la compañía Pearson. Para mayor información del tema véanse los trabajos de Armando Rojas $(1995,2004)$ y para una comparación de esta vía con otras líneas del ferrocarril de América y España a finales del siglo xIX y principios del xx, véanse las conclusiones de Sedano (2012).

\section{()(1) $\$$}


una de las primeras estaciones ferroviarias del proyecto de Pearson, ya que al momento de planear el traslado de los talleres de Coatzacoalcos a Rincón Antonio se advirtieron las ventajas que ofrecía la zona: una abundante cantidad de agua y un mejor clima. La transformación de esta ranchería con la instalación de los talleres fue monumental y trascendental, y al paso de los años se convirtió en uno de los centros urbanos más importantes de toda la vía. ${ }^{8}$

Debido a la necesidad de mano de obra para la construcción del ferrocarril, los primeros pobladores de Rincón Antonio provinieron de toda la región del istmo oaxaqueño y veracruzano. Posteriormente se incorporarían ingleses, "americanos", chinos y sirio-libaneses que tenían alguna relación con la actividad ferrocarrilera (Cérbulo et al., 2006, pp. 16-17).

Después de que la compañía del ferrocarril trasladara los talleres de reparación a Rincón Antonio -y no las oficinas de administración, como era la idea-, construyó la casa de fuerza motriz para las locomotoras, una planta de luz y de hielo, a continuación se crearon espacios habitacionales para los habitantes y un club destinado a los inversionistas, jefes y personajes influyentes para que se divirtieran, entre otros aspectos. Con el paso del tiempo, Rincón Antonio se convirtió en la zona más importante de la región: en 1906 cuando alcanzó la categoría política de pueblo, y en 1907 -año de la inauguración del Ferrocarril Nacional de Tehuantepec-cambió su nombre oficial por el de Matías Romero ${ }^{9}$ (cabecera del nuevo municipio del distrito de Juchitán).

En 1902, la compañía Pearson se refirió a Rincón Antonio como un centro de población que crecía de forma constante y era necesaria la construcción de casas para los habitantes (trabajadores y comerciantes), pues varios de ellos dormían a la intemperie o tenían que regresar a su lugar de origen. Sin embargo, no fue tanto una preocupación por los "habitantes", sino una manera de tener el permiso para retener y conservar la mano de obra y mantener el flujo comercial que sucedía en la zona; dicha situación se debió a que los trabajadores sólo estaban una temporada y después regresaban a su

${ }^{8}$ Cabe mencionar que J. Glasgow, empleado del ferrocarril, señalará como una de las causas de la huelga dicho traslado.

${ }^{9}$ Actualmente, Matías Romero es un municipio hasta cierto punto importante debido a sus diferentes actividades económicas y por resaltar su historia como centro ferrocarrilero. La historia de Rincón Antonio es una muestra clara de cómo con la idea de "progreso" se construyen ciudades por aquí y por allá buscando mejorar lo pasado; sin embargo, cuando se ha alcanzado la meta deseada, se busca una nueva y así el ciclo se repite, una y otra vez. ¿Cuántas ciudades y puertos quedaron en el recuerdo del pasado?, ¿quién cuenta sus historias, después de que el ferrocarril ya no pita?, ¿dónde se quedaron las sociedades que vieron pasar al ferrocarril? Sedano, 2012, pp. 129-130.

\section{(이요}


lugar de origen cuando iniciaban las temporadas de siembra, por ello la urgencia de ofrecer cierta estabilidad al empleado. El argumento se inserta en la súplica que realizó la compañía al gobierno para que le permitiera vender lotes de tierras en esa zona, como lo manifestó en un documento:

El punto mencionado no es una simple estación de ferrocarril sino que constituye una población numerosa con necesidades [...] En la actualidad carecen de habitación humana gran número de sus pobladores algunos de los cuales duermen y viven á la intemperie; y otros que no se resignan á soportar estas incomodidades, están obligados a recorrer largas distancias para ir a pernoctar con sus mercancías y regresar al día siguiente á expandirlas, y en general se encuentran en la imposibilidad de fijar su negociación de tal suerte que pueden disponer de un lugar seguro y adecuado para almacenes. [...] El resultado de estas dificultades es y ha sido que padezca mucho el estado sanitario de la población y que los efectos de primera necesidad, [el] almacén [y los] precios considerablemente elevados que hacen muy difícil la existencia de los individuos que trabajan en los diversos departamentos del ferrocarril de aquel lugar. La compañía está pues, seriamente amenazada de un inevitable aumento en la escasez de brazos y quizás en la paralización de sus trabajos originada por [la] circunstancia. ${ }^{10}$

La cita nos permite analizar que los objetivos de la compañía de Weetman Pearson no estuvieron pensados en la mejora de la región o de sus habitantes, sino en construir una ruta comercial que conectara dos océanos y las ganancias a futuro para los empresarios y el gobierno de Díaz. El surgimiento de una huelga en algún punto de la línea férrea era un freno que no se podía permitir, porque afectaría de manera importante la inversión que se le dio al ferrocarril. Quizá es por ello que no tengamos conocimiento de la huelga en ningún periódico y que la solución siempre fuera despedir a los trabajadores. Todo ello acorde con la ideología del gobierno de Porfirio Díaz, que era darle prioridad a la "locomotora del progreso".

En el caso de Coatzacoalcos, este punto pertenecía a Veracruz, que fue uno de los estados que logró un crecimiento económico importante porque contaba con uno de los primeros puertos en recibir mercancías de Europa y

${ }^{10}$ Fraccionamiento de terrenos para la ubicación de las construcciones en Rincón Antonio, Oaxaca. 1902. Fondo de Secretaría de Comunicaciones y Obras Públicas. 2/776-1. AGN, México.

\section{()(1) $\$$}


Estados Unidos. Como todo proceso de modernización, varias ciudades de la zona portuaria lograron obtener más beneficios que otras, ese fue el caso de Coatzacoalcos, la cual contaba con la afluencia del río del mismo nombre.

Coatzacoalcos era considerado un pueblo insalubre y de constantes epidemias. Emprendió el cambio con los primeros trabajos de construcción de la vía y del puerto, pues empezaron a surgir asentamientos de carpinteros, marineros y comerciantes. Sumado a ello estuvieron las obras realizadas por la empresa Pearson como los muelles, las oficinas ferroviarias y de telégrafos, los talleres y los almacenes, permitiendo que poco a poco la ciudad fuera más atractiva para diferentes grupos sociales. Es de destacar que también se comenzó a construir un centro de población más adecuado a las necesidades que el proceso de modernización estaba generando, como fue el trazado de las calles; aunque ya muy tarde, en 1909, la compañía Pearson logró construir un sistema de drenaje y abastecimiento de agua potable. Alcanzaría la categoría de ciudad en 1911 (Saraiba, 2005).

Como resultado, a partir de la construcción de las dos bases ferroviarias, ambas ciudades desarrollaron un crecimiento económico en la época mencionada. Permitieron generar un mercado interno más dinámico y con más participación de regiones que no lo hacían, aunque otros centros de población tuvieron que competir de manera desigual, al no contar con recursos naturales que ofrecer. Una de las soluciones que se buscó fue hacer de las ciudades centros ferrocarrileros, es decir, los servicios que ofrecieron tenían que ver con las actividades de las líneas férreas. Regresemos a narrar qué sucedía con los trabajadores objeto de nuestro interés.

\section{LOS MECÁNICOS Y FOGONEROS DEL FERROCARRIL DEL ISTMO}

¿Qué actividades realizaban un mecánico y un fogonero?, ¿cuál era el sueldo para ambos trabajadores en 1903?, ¿qué es un taller ferrocarrilero?, ¿qué otros empleos existían en los lugares de trabajo? Las respuestas a estas preguntas nos permitirán entender el surgimiento de la huelga en el Ferrocarril Nacional de Tehuantepec, así como las peticiones y argumentos que quedaron escritos en los telegramas. ${ }^{11}$ Por lo que se refiere a la historiografía, Armando

${ }^{11}$ Cabe resaltar que nuestra pretensión no es abarcar todo el tema sobre los mecánicos y demás empleados del ferrocarril; por el contrario, hacemos una advertencia: a la historia que

\section{()(1) $\$$}


Rojas es quien se ha encargado de reconstruir cómo fue la organización del trabajo de la empresa de la vía del istmo, permitiendo observar con mayor precisión los diferentes empleos que hicieron posible llevar con cierto éxito la construcción del ferrocarril. Si bien su estudio logra explicar de manera precisa las funciones de los empleados de más alto rango, en el caso de los trabajadores de menor jerarquía la información proporcionada se limita a decirnos sus funciones y los sueldos, sin ofrecernos una interpretación de esos datos como lo hace con los primeros (Rojas, 1995, 1996, 2004). Guillermo Guajardo (2010), por su parte, ha tratado de observar la relevancia que le han dado los gobiernos al desarrollo de la enseñanza técnica que se les daba a los trabajadores y la capacidad para generar la tecnología que necesitaba el ferrocarril en un periodo de 100 años (1850-1950). En el caso del porfiriato, el autor menciona que el saber tecnológico era empírico, pues en aquella época no se desarrolló un sistema de educación enfocado a los transportes ferroviarios, recayendo la capacitación muchas veces en los gremios ferrocarrileros. Si bien el estudio de Guajardo (2010) nos muestra las deficiencias que tuvo la enseñanza técnica para capacitar a los trabajadores en su labor, falta precisar esas generalizaciones en un caso concreto, como lo fue el Ferrocarril Nacional de Tehuantepec. En seguida, observaremos cuáles eran los componentes de un taller, las funciones que realizaban los trabajadores y los sueldos que ganaban. Además, se analizarán las opiniones que tenían los trabajadores de más alto nivel con respecto a los huelguistas de 1903.

Las empresas ferroviarias se organizaban en divisiones (unidades de funcionamiento administrativo), a su vez estas se dividían en áreas. El encargado de cada área era el superintendente (representante de los intereses de la empresa y jefe máximo de todos los encargados de los diferentes departamentos). Una de las áreas dentro de esa división era la jefatura de taller mecánico, donde se realizaba la actividad de mantenimiento y reparación de todo el equipo motriz y rodante que se ocupaba a lo largo de la vía del ferrocarril, además de la maquinaria que se utilizaba para dichas funciones. En los talleres se arreglaban las máquinas y el resto del material rodante, las cadenas y pernos de enganche entre ténders ${ }^{12}$ y máquinas; se componían

contaremos aún le falta una mayor explicación y hacer matices más profundos, precisamente por la carencia de fuentes. Sin embargo, podemos también decir que lo dicho hasta aquí es un punto de partida para una investigación futura sobre los trabajadores, uno de los elementos mayormente olvidados del Ferrocarril Nacional de Tehuantepec.

${ }^{12}$ Vagón de ferrocarril que se engancha a la locomotora y transporta el agua y el combustible necesarios para el viaje.

\section{()(1) $\$$}


varias herramientas de la fragua, forjar grapas para cadenas de seguridad, y otras piezas de máquinas y maquinaria; hacían moldes y se cernía arena para fundir fierro; ajustaban cinceles, brocas y punzones para el taller; pintaban y tapizaban casas; hacían modelos para sapos de cambio; reparaban furgones; habilitaban madera para armones de manubrio para la vía; reparaban y ponían mesa nueva a las plataformas; reparaban casas y aserraban madera para edificios y material rodante (Guajardo, 2010, pp. 42-43; Rojas, 2004, pp. 205 y 222). En suma, en la historia del Ferrocarril Nacional de Tehuantepec existieron tres talleres o "casas rodantes" a lo largo del tendido de la vía, estos fueron los de Rincón Antonio, Coatzacoalcos y Salina Cruz; los dos últimos no fueron relevantes en comparación con el primero.

Los oficios en estos talleres eran los de mecánicos, albañiles, pintores, obreros, hojalateros, moldeadores, fundidores, modelistas, herreros, calderos y carpinteros. En la huelga se puede mencionar la participación de los mecánicos, no existe la duda de que los demás oficios puedan pertenecer a los que se ha llamado "empleados del ferrocarril" (Guajardo, 2010, p. 44). Es decir, se puede notar que el taller era un lugar en donde también se establecían diferentes relaciones sociales e intercambio de ideas, quizá muchas de ellas tenían que ver con los problemas de sueldos y jornadas que compartían entre todos por las diversas jerarquías que tenían.

Podemos manifestar que los fogoneros pertenecían a un espacio diferente de los mecánicos: ellos formaron parte de "los trenes en movimiento" donde se encontraban los conductores, maquinistas, fogoneros, veladores, de máquinas, garroteros y "pasa carbón" o "pasa leña" (Guajardo, 2010, p. 44). También las locomotoras sirvieron como un espacio de sociabilidad, con una ventaja mayor que la de los talleres, ya que por el constante trajinar de los trenes, los fogoneros divulgaban y recopilaban las preocupaciones de sus compañeros trabajadores.

Los talleres fueron el escenario ideal para generar una movilización laboral porque se convertían en la base de operaciones para que la vía del istmo pudiera funcionar a la perfección, es decir, tenían una posición estratégica central; sin embargo, en el caso de los trabajadores de la huelga de 1903, ellos no realizaron ninguna actividad en contra del ferrocarril, por el contrario, decidieron alejarse de los talleres. Como puede observarse, para los mecánicos y sus compañeros su enemigo era la empresa, por la manera como hacían el reparto de los dividendos. Así lo dijeron los mecánicos, con respecto al proceder de los fogoneros: "pero que nadie pidiese sus fondos en término de ocho días que al fenecer dicho plazo si no ha resuelto 'la Empresa' nada favorable que

\section{()(1) $\$$}


podían separarse para poder ganarse la vida honrosamente como hasta la presente lo habían hecho, encargando al Mayor orden y buena conducta procurando lo menos posible transitar por los talleres y divisiones del ferrocarril". ${ }^{13}$

La pregunta es ¿cuánto ganaban aquellos mecánicos, los fogoneros y demás trabajadores? La respuesta es relevante porque nos permitirá dar una explicación más clara de las demandas que exigían los huelguistas para llegar a un acuerdo con la empresa Pearson. Las fuentes utilizadas para el año de 1903 son poco claras ya que la compañía Pearson no hacía listas de raya como se hacía antes de su concesión; por ello, los datos que ofrecemos son una muestra de los sueldos de años anteriores y posteriores a la huelga, así observaremos si cambiaron, y de qué manera pudo suceder (véase cuadro 1).

Los sueldos aparecen en dos niveles, el salario más bajo lo ganaban los aprendices, y el más alto, el maestro de cada oficio. Es difícil no pensar que la organización dentro de los talleres ferroviarios no funcionara como en los talleres artesanales (maestros-aprendices); recordemos que para estos años no está todavía definida del todo una clase trabajadora pese a existir, gracias al papel antagónico que los contraponía a sus patrones y al avance tecnológico de la época, ciertas características de ella; en este momento aún de transición, seguían predominando entre los trabajadores jerarquías del trabajo artesanal que se irán perdiendo con el transcurrir del tiempo. ${ }^{14}$

Los años escogidos tienen un significado: 1890 es anterior a la etapa de Pearson como constructor; 1899 es el año que se hace oficial el contrato con dicha casa empresarial; 1907 el de la inauguración del Ferrocarril del Istmo. Entonces, un mecánico maestro llegó a recibir un sueldo de cinco pesos por día en la última década del xIX, y para el inicio de la siguiente su sueldo disminuyó casi a la mitad, al percibir por su trabajo sólo 2.60 pesos; sucede lo mismo con los fogoneros, su sueldo más alto fue de 2.50 pesos, y para la inau-

${ }^{13}$ Huelga de maquinistas, empleados y fogoneros. 15 de abril de 1903. Fondo Secretaría de Comunicaciones y Obras Públicas, 2/673-1. AgN, México.

${ }^{14} \mathrm{Si}$ bien las fuentes y la historiografía del Ferrocarril Nacional de Tehuantepec no dicen nada al respecto, en estudios de otras vías como las de Acámbaro, Guanajuato, Emma Yanes (1991) ha dicho lo siguiente: "En la octava década del siglo XIX se desplazaron múltiples maestros de los [talleres] artesanales a los ferroviarios. Sus hombres contaban ya con experiencia en los trabajos de herrería, fundición, pintura, carpintería, y poseían una tradición de conocimiento que pusieron al servicio de las empresas extranjeras [...] Cada departamento contaba con su dinámica propia y esta era parecida a la de los talleres artesanales [...] Pero no todos los talleristas tenían un pasado artesanal." Suponemos que en los talleres del Nacional de Tehuantepec sucedió lo mismo (pp. 64-65).

\section{()(1) $\$$}


Cuadro 1. Salarios que se pagaban a los trabajadores del Ferrocarril Nacional de Tehuantepec $(1890,1899,1907)$

\begin{tabular}{|c|c|c|c|}
\hline $\begin{array}{l}\text { Denominación del } \\
\text { puesto }\end{array}$ & (1890) & $\begin{array}{c}\text { Salario por día } \\
\text { (1899) }\end{array}$ & (1907) \\
\hline Carpintero & 0.75 a 2.50 pesos & 1.50 a 4.00 pesos & 2.16 pesos \\
\hline Agente de estación & & 3.29 pesos & 3.29 pesos \\
\hline Velador & 0.50 a 0.75 pesos & 0.75 a 1.50 pesos & 1.02 pesos \\
\hline Guarda vías & 0.62 a 0.63 pesos & 1.00 peso & 1.02 pesos \\
\hline Herrero & 0.50 a 2.00 pesos & 1.50 a 5.00 pesos & \\
\hline Mecánico & 1.25 a 5.00 pesos & 3.50 a 5.00 pesos & 2.60 pesos \\
\hline Maquinista & 0.75 a 1.50 pesos & 4.94 a 5.70 pesos & 5.68 pesos \\
\hline Conductores & & 4.11 pesos & 7.53 pesos \\
\hline Fogoneros & 0.75 a 1.00 peso & 1.50 a 2.50 pesos & 1.68 pesos \\
\hline Telegrafistas & & 1.75 a 2.14 pesos & 3.49 pesos \\
\hline Operarios talleres & 0.50 a 0.75 pesos & 1.00 a 1.50 pesos & 1.90 pesos \\
\hline Peones de la vía & 0.50 pesos & 0.50 pesos & 0.95 pesos \\
\hline Cabos de sección & 0.75 a 1.00 peso & 1.50 a 2.00 pesos & 2.06 pesos \\
\hline Albañiles & 1.12 a 3.00 pesos & & \\
\hline Sobrestantes & 2.0 a 2.50 pesos & 2.25 a 2.50 pesos & \\
\hline Bodeguero & 0.50 a 0.75 pesos & 1.25 a 2.47 pesos & \\
\hline Garrotero & 0.87 pesos & 1.75 a 2.96 pesos & \\
\hline
\end{tabular}

Las cursivas indican los sueldos de los trabajadores que hemos tratado aquí, así el sueldo más alto es el de los maestros y el más bajo es de los aprendices.

Fuente: Rojas (1996, p. 196).

guración se redujo un peso al quedarse en 1.68 pesos. El cuadro 2 nos ofrece los sueldos mensuales y anuales de los mecánicos y fogoneros, podemos decir que mensualmente un mecánico maestro ganó 155 pesos en 1890, y para 1907 se disminuyó a 80.60 pesos, y para un aprendiz de mecánico su sueldo más alto fue de 108.50 pesos en 1899. Los fogoneros obtuvieron su sueldo mensual más alto en 1907, cuando ganaron 52.08 pesos, sin importar que fueran maestros o aprendices, pues se unificaron los sueldos. En 1890, el sueldo anual de un mecánico maestro, que ganaba cinco pesos, fue de 1825 pesos, y en 1907 disminuyó a 949 pesos; los fogoneros recibieron por año entre 273.75 pesos (1890) a 613.20 pesos (1907). 


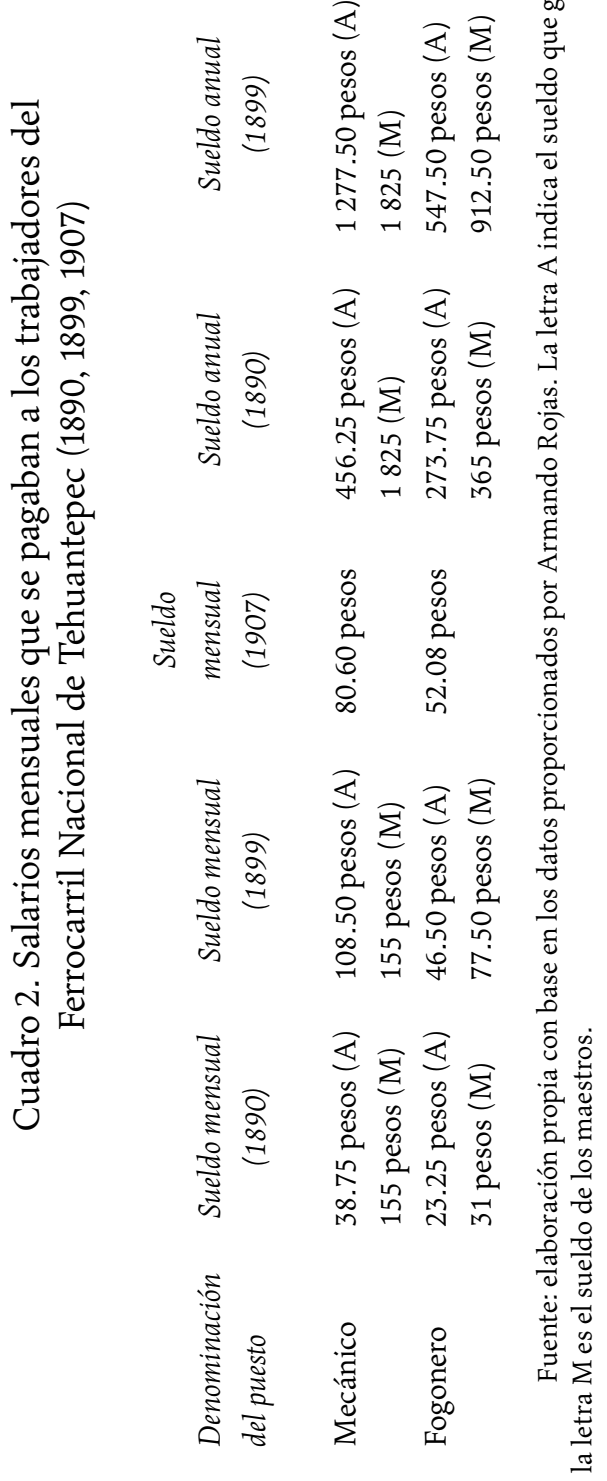

\section{(ㄷ)(1)(8)}


Los datos anteriores se calcularon considerando que para esa época los trabajadores no tenían un día de descanso, por ende, trabajaban los 365 días del año; asimismo, se tiene que quitar lo que les descontaban por la renta de la casa (propiedad de la empresa) y el mantenimiento del hospital. Los sueldos aumentaron en 1899 para disminuir en 1907, año de la inauguración del Ferrocarril del Istmo. ${ }^{15}$

A partir de esos datos podemos explicar las peticiones que hicieron los huelguistas: el respeto al empleo de cada trabajador pese a la huelga, que el sueldo que recibirían fuera de acuerdo con las actividades que se realizaban (el aumento en los sueldos de 10\% a los empleados de Coatzacoalcos, $15 \%$ a los de Rincón Antonio, 10\% a los nocturnos y 50\% en caso de horas extras) y justificación clara en caso de despido. ${ }^{16}$

En 1903, los trabajadores exigían un aumento de entre 50 centavos y 2.50 pesos sobre su sueldo. Si consideramos que el sueldo hubiera sido de cinco pesos de un mecánico y 2.50 de un fogonero, con una jornada de nueve horas diarias dividido en dos turnos: 6:00 a. m. a 11:00 a. m. y 12:00 p. m. a 4:00 p. m., y el aumento que hubo entre 1891 y 1908 en el precio de maíz, frijol, chile, trigo y harina, parece que las exigencias de los mecánicos y sus compañeros eran bajos respecto a las ganancias que generaba el ferrocarril (por ejemplo, en 1903 el ferrocarril tuvo una remuneración anual de 1009271 pesos, siendo que sólo trasportaba carga local). ${ }^{17}$

Cuando se habla de los sueldos, interesa mencionar los pagos que se hicieron por el arrendamiento de las viviendas y el porcentaje para el fondo del hospital. En otras palabras, a los empleados y operarios del ferrocarril se les permitió construir casas al lado de las vías, al suroeste del patio (lugar donde se armaban los trenes, se clasificaba los vagones y se formaban los diferentes

${ }^{15}$ Una comparación con los sueldos de 1889 que recibían los trabajadores del departamento de fuerza motriz de San Luis Potosí nos permite observar que llegaron a ser más bajos que los del Istmo de Tehuantepec. En otras palabras, según Luz Carregha: "Los salarios variaban entre $\$ 1.00$ y $\$ 4.50$ por jornada diaria, excepto los maquinistas y fogoneros quienes se les pagaba por viaje y distancia recorrida. El promedio del sueldo mensual que percibían estos en el caso de trenes de pasajeros era de $\$ 180$ y $\$ 160$, respectivamente, mientras quienes conducían ferrocarriles de carga recibían $\$ 100$ y $\$ 80$ en el mismo orden." Los fogoneros percibían un sueldo de 80 a 160 pesos por su trabajo que fue más alto que el del Istmo, el cual era de 2.50 pesos, aunque no sabemos si la aclaración que hace la autora -viaje y distancia recorrida-sea la misma para nuestro ferrocarril. Carregha (2009).

${ }^{16}$ Huelga de maquinistas, empleados y fogoneros. 15 de abril de 1903. Fondo Secretaría de Comunicaciones y Obras Públicas. 2/673-1. Agn, México.

${ }^{17}$ Con respecto a los datos de la inflación por año véase Rojas (2004, pp. 196 y 222) y de las ganancias del ferrocarril a Garner (1998, p. 117).

\section{(이요}


convoyes) y fuera de la cerca (Guajardo, 2010, pp. 43 y 226-227). Uno de los ejemplos donde podemos ver esa situación es Rincón Antonio. Mientras que en el caso del hospital desconocemos cuánto se les descontaba en sí, pues sólo sabemos que se hacía según el sueldo que ganaban.

Por último, las opiniones vertidas en los telegramas enviados por J. Glasgow, nos permiten ver cuánto se valoraba el trabajo de los huelguistas y las opiniones que tenían sobre ellos en el año de 1903. Los trabajadores, según esos puntos de vista, eran "objetos intercambiables" que en cuanto dejaban de ser "útiles" podían ser remplazados por otros, por uno "mejor"; se hacía referencia también a la seguridad que tenían las empresas en saber que lo que sobra, en una sociedad donde domina su poder, es la mano de obra barata y disponible, un "ejército de reserva" laboral pues, como en todo tiempo, el capital encuentra un "necesitado". Ello no va en contradicción con la falta de trabajadores para el ferrocarril al inicio de la construcción, ya que una de las grandes ventajas que ofreció México a los inversionistas extranjeros fue manos que quisieran trabajar en cualquier parte del país o la disposición del gobierno para obligar a los habitantes a hacerlo. La siguiente cita ejemplifica lo anterior:

El tráfico no se interrumpió y en nada se ha perjudicado la construcción, pues [los] trabajos [quedaron] sin interrupción [,] únicamente quedo interrumpido el trabajo en [el] kilómetro 17 por un solo día y haberse tenido que suspender por cuatro días el tren de carga de Coatzacoalcos [;] por haberse al principio[, los] fogoneros adheridos al movimiento pero luego desistieron y desde [el] sábado todos los [de]más trenes de trabajo siguen en estado normal faltando solo parte del personal en los talleres que será remplazaron [sic] [por] personal nuevo de México de mejor clase. ${ }^{18}$

Para comprender la huelga de 1903 era necesario, sin duda alguna, conocer quiénes eran y qué hacían los mecánicos, fogoneros y demás empleados que participaron en la huelga. Lo contado en los párrafos anteriores tuvo la intención de mostrar los espacios en que se movían dichos empleados, sus funciones y sus sueldos, con el fin de poder darle una explicación al porqué del surgimiento de un conflicto laboral en los talleres de Rincón Antonio.

18 "En nada absolutamente se ha perjudicado el ferrocarril por este motivo [,] pues muchos inútiles que serán remplazados sin dificultades actualmente sigue[n] el trabajo en los talleres de Rincón Antonio aunque con personal reducido y tenemos obreros nuevos en camino." Las cursivas son mías en ambas citas. Huelga de maquinistas, empleados y fogoneros. 20 de abril de 1903. Fondo Secretaría de Comunicaciones y Obras Públicas. 2/673-1. AGN, México.

\section{()(1) $\$$}


Asimismo, nos sirve para avanzar en la demostración de que, más allá de ser un simple antecedente o un fracaso, la huelga de 1903 es otro ejemplo claro de cómo los trabajadores comenzaron a manifestar su fuerte descontento por los graves problemas que pretendía cubrir el gobierno con la construcción del "eje comercial del mundo", como llegó a conocerse también la vía del istmo y que permeaba la opinión de los empleados más altos del ferrocarril.

\section{LA UNIÓN DE MECÁNICOS MEXICANOS Y SU PARTICIPACIÓN EN LA HUELGA DE 1903}

Durante el último periodo del porfiriato las huelgas estaban prohibidas y se castigaba a todos aquellos que exigieran mayores sueldos o reducción de jornadas. Lo único permitido eran las sociedades mutualistas entre obreros y artesanos (Herzong, 2005, pp. 52-53). Entonces ¿qué era la Unión de Mecánicos Mexicanos en 1903?, ¿cómo incidió la manera en que se formó la Unión en la huelga de los talleres?, ¿participaban los trabajadores del Istmo en ella?, ¿cuál fue el resultado que obtuvieron los trabajadores con la participación de la Unión? Responder a estas preguntas nos ayudará a comprender cómo la huelga de 1903, pese a no haber tenido una repercusión amplia, fue un primer intento de los trabajadores ferrocarrileros por organizarse como grupo para obtener beneficios laborales frente al poder de las empresas. Las acciones que llevó a cabo la Unión son una muestra clara de la transición que se estaba dando de las sociedades mutualistas al sindicalismo.

A la mitad de esa transición surgieron las sociedades de resistencia: agrupaciones donde las demandas se encaminaban a buscar mejoras laborales, contratos colectivos y mayor participación dentro de las empresas. Las acciones que utilizaban eran el boicot y la huelga, a diferencia de las mutuales, que buscaban ayudar a sus miembros por medio de cuotas en caso de enfermedad, prisión o muerte, además de suponer un acuerdo entre los intereses económicos y los del trabajador. ${ }^{19}$ Las sociedades que tuvieron mayor participación fueron las de los ferrocarrileros debido al crecimiento tanto en

${ }^{19}$ John Lear (1997, pp. 275-309) tiene una opinión distinta en cuanto al cambio de las sociedades mutualistas, pues menciona que las mutuales lograron sobrevivir hasta mucho después del porfiriato y que fueron desapareciendo cuando se aceptó a los sindicatos y las demandas sobrepasaron la simple ayuda mutua en caso de adversidad. Asimismo, es de destacar que el autor no menciona algún cambio dentro de las sociedades mutualistas a finales del siglo XIX. Si bien estoy de acuerdo en varios de los planteamientos que hace el autor, me parece que

\section{()(1) $\$$}


organización como en acción. La mayoría de estas sociedades estaba compuesta por especialidades - por ejemplo, la de mecánicos, la de fogoneros o la de calderos-. ${ }^{20}$ Una de las sociedades más importantes fue la Unión de Mecánicos Mexicanos fundada por Teodoro Larrey ${ }^{21}$ en la ciudad de Puebla el 28 de agosto de 1900. En el Acta Primordial de los Estatutos y Reglamentos General e Interior de la Unión se establecía lo siguiente:

Establecer en la República una Sociedad exclusivamente de Mecánicos que sin distinción de nacionalidad acepte en sus seno a todo los obreros del ramo, vele constantemente por sus intereses de trabajo, progreso y perfeccionamiento y procure para sus afiliados la remuneración que justa y equitativamente merece por sus labores, impidiendo inconsecuentes privilegios que por razón de extranjería han hecho del obrero mexicano un instrumento injusto de odiosas especulaciones por parte de determinadas empresas, fábricas, talleres, etc., que han creado exclusivismos perjudiciales para el obrero nacional (Shabot, 1982, p. 69; Woldenberg, 1980, p. 81).

En otras palabras, la Unión indicaba que no pretendía ser una sociedad mutualista que ayudara en caso de adversidad, sino una agrupación de empleados que buscaba beneficios laborales para un conjunto en específico, como lo eran los mecánicos, frente al predominio de los extranjeros tanto en los salarios como en el trato.

Debido a que la Unión comenzó a tener éxito en varios lugares del país, en 1901 sus fundadores fueron arrestados por la organización de una huelga en Puebla (Woldenberg, 1980, p. 10; Rodea, 1944, p. 98). ${ }^{22}$ Esto implicó el declive de la asociación, quedando en 1903, según la historiografía, solamente la sucursal de Chihuahua, encabezada por Silvino Rodríguez, quien se encargaría de reorganizar y fortalecer a la asociación en los años siguientes.

No obstante, es paradójico que en el mismo año la sucursal número seis de la Unión en Rincón Antonio decidiera lanzar una huelga en los ta-

las sociedades mutualistas sí sufrieron cambios mucho antes de la existencia de los sindicatos, como fueron las peticiones para diversos compañeros de trabajo y no sólo de un sector.

${ }^{20}$ Es importante decir que empezarían también a existir grandes organizaciones que buscaban la unificación de varios componentes del gremio, es el caso de La Gran Liga.

${ }^{21}$ Terry Larrey era mecánico y durante la etapa en que prevalecían los jefes extranjeros en el funcionamiento y la administración de las líneas, logró ascender a maestro (Shabot, 1982, p. 106).

${ }_{22}$ Ninguno de los dos ofrece mayor explicación de por qué se debilitó la Unión de Mecánicos Mexicanos.

\section{()(1) $(3$}


lleres que ahí se encontraban, ya que se supone que para este año comenzó para la agrupación una nueva restructuración, así como por ser el quinto año de trabajo en la reconstrucción del Ferrocarril Nacional de Tehuantepec. En otras palabras, el contexto en el que se inserta la huelga de 1903 es un clima de inestabilidad para la propia Unión, que no contaba con los elementos necesarios para lograr una huelga exitosa y por tener una compañía constructora que estaba buscando ante todo quedar bien con el gobierno.

Una de las primeras acciones de la Unión fue integrar a los empleados de Coatzacoalcos al paro de labores de 1903, lo que nos permite observar el hecho fue la unión de varios sectores de trabajadores que permitía generar mayor presión ante la empresa. Es cierto que la fuerza de estos dos grupos no creó una gran coerción en 1903, pero sirvió para mostrar que la Unión no sólo estaba preocupándose por los intereses de los mecánicos, sino que buscaba ampliar sus acciones a otros sectores.

En el primer párrafo del último telegrama del 28 de abril de 1903, lo que nos muestra es un acercamiento de la Unión con el secretario Fernández a través de una comisión que le expusiera "la asociación y actitud de los huelguistas". El uso de comisiones fue uno de los primeros intentos de los trabajadores por acercarse a las autoridades como intermediarios con el fin de obtener sus peticiones frente a la compañía. Al paso de los años se buscaría también una representación dentro de las empresas para poder tomar decisiones a su favor, aunque las comisiones no se eliminarían. Estas son las palabras de la Unión en ese telegrama:

Deseando la "Unión de Mecánicos Mexicanos" de una manera correcta y pacífica arreglos a las dificultades que últimamente se han suscitado entre algunos de nuestros asociados y la compañía arrendataria del ferrocarril del Istmo hemos creído lo más oportuno y lo más halagüeño por los beneficios resaltados que esperamos obtener, dirigimos a Ud. Sr. Ministro confia[n]do la asociación en sus rectos principios de Justicia, su elevado criterio, preclaro talento y al efecto nombro en comisión para acercarse a Ud. a los señores Agustín Arenas, Melclizades [Melquiades i?] Jiménez, Carlos B. Ballartet y Agustín Álvarez.

Estos señores que llenan las suficientes facultades para el arreglo del asunto, informarán a Ud. verbalmente de la situación y actitud de los huelguistas, así como de las intenciones que obligan para lo futuro. ${ }^{23}$

${ }^{23}$ Huelga de maquinistas, empleados y fogoneros. 28 de abril de 1903. Fondo Secretaría de Comunicaciones y Obras Públicas, 2/673-1. Agn, México.

\section{()ㅜ(1) $\$$}


Siguiendo con este telegrama, la Unión hace una precisión al contexto en el que se desarrollaba la huelga de 1903. El ejemplo más claro es cuando la Unión enfatiza "que sólo tratan por medio de su trabajo vivificar aún más la brillante marcha de paz y progreso que el actual Gobierno con sabiduría ha cimentado en nuestra amada Patria". ${ }^{24}$ Dicho argumento, en apariencia, no buscaba atacar a la administración de Porfirio Díaz, sin embargo, una característica de estas sociedades de resistencia fue usar la huelga como instrumento para hacer un alto en el camino y decirle al otro que no se estaba de acuerdo con el orden impuesto. Con el paso del tiempo, las sociedades de resistencia empezaron a tener un carácter político e ideológico más definido, hasta llegar a ser agrupaciones sindicales.

El telegrama del que venimos hablando termina con la siguiente idea: "No queriendo por un momento que se crea que tratamos de abrazar de una posición bien definida y delicada por tratarse contra estranjeros." ${ }^{25} \mathrm{Si}$ bien puede resultar una contradicción de la Unión con respecto a sus estatutos, creo que por "estranjeros" se refiere a la nacionalidad británica de la empresa de Weetman Pearson, más que a los trabajadores; entonces, a lo que se refería la Unión era a que no estaban en contra del capital extranjero sino de las condiciones laborales que les ofrecía la compañía a sus agremiados. Para estos años se criticaba al gobierno de Díaz de vender la patria a los extranjeros, y es que muchos de los discursos que daba el presidente hacían referencia a la relevancia del capital extranjero para que se lograra el tan anhelado progreso que beneficiaría al país, lo que no decía es que la mayoría de la sociedad estaba fuera del "país" al que hacía alusión. Por eso la insistencia de la Unión de tratar de alejarse de esa crítica.

Una pregunta relevante es saber si algunos de los huelguistas pertenecieron a la Unión. No obstante, es difícil saberlo, pues no existe un registro que nos ayude a resolver dicha duda. Podemos decir, sin estar seguros del todo, que varios de los nombres que aparecen en el último telegrama pueden ser mecánicos pertenecientes a dicha agrupación, ellos fueron Agustín Arenas, Melclizades [sic] Jiménez, Carlos B. Ballartet y Agustín Álvarez. Asimismo, quizá la participación de la Unión se debió a la petición de algunos

${ }^{24}$ Huelga de maquinistas, empleados y fogoneros. 28 de abril de 1903. Fondo Secretaría de Comunicaciones y Obras Públicas, 2/673-1. Agn, México.

${ }^{25}$ Huelga de maquinistas, empleados y fogoneros. 28 de abril de 1903. Fondo Secretaría de Comunicaciones y Obras Públicas. 2/673-1. Agn, México.

\section{()ㅜ(1) $\$$}


miembros, como fue el caso de Jesús Mendoza, quien prestaría su casa para una de las reuniones y en la cual se escribió el pliego petitorio. ${ }^{26}$

La importancia de la huelga de 1903 no se debe juzgar a la luz del éxito o del fracaso que tuvieron las acciones de la Unión sino por la trascendencia que tienen estos primeros intentos de los trabajadores por tratar de alzar la voz y manifestar su desacuerdo frente al avance del poder económico que tenían las empresas en México, apoyadas sin duda por el gobierno de Díaz. La experiencia de las huelgas que surgen en esta época será relevante para los años siguientes, donde se seguirá luchando sin una legislación que los respalde y la preferencia seguirá estando del lado del capital. Las cosas cambiarán hasta 1917, cuando se acepten los sindicatos y su derecho de huelga, aunque eso tampoco implicó necesariamente y en lo inmediato un triunfo para el trabajador.

\section{CONCLUSIONES}

En 1907 fue inaugurado el Ferrocarril Nacional de Tehuantepec. La llegada de un barco proveniente de Hawái a la estación de Tehuantepec dio inició al acto; traía una carga de sacos de azúcar que comenzó a descargar Porfirio Díaz para colocarlos en el vagón del ferrocarril, todo como símbolo de la apertura del comercio internacional. De esta manera, se quería demostrar que México pertenecía al "concierto de las naciones civilizadas". ${ }^{27}$ Sin embargo, en los talleres, en las oficinas, en las estaciones y en los mismos trenes

26 "Patria y Libertad. El Presidente de Unión de Mecánicos Mexicanos Suc. No. 6 R. S. Gallinar, en sesión general del día 14 del presente á las 11 h 20 m a.m. reunidos todos los obreros del taller del Ferrocarril Nacional de Tehuantepec en la casa del Sr. Jesús Mendoza, Socio de la Unión de Mecánicos Mexicanos bajo la presencia del socio Ramón S. Gallinar con asistencia de once socios." Huelga de maquinistas, empleados y fogoneros. 15 de abril de 1903. Fondo Secretaría de Comunicaciones y Obras Públicas. 2/673-1. AgN, México.

27 Sin embargo, tan sólo algunos años después, aquellos hombres verían cómo el ferrocarril que construyeron se fue convirtiendo en un "elefante blanco", como se decía en la época por varios sectores de la sociedad, y es que la revolución mexicana, el Canal de Panamá y el inicio de la primera guerra mundial trajeron consigo que gran parte del "progreso" alcanzado durante el porfiriato, se convirtiera en un "castillo de naipes". Tras la gran derrota de Díaz a manos de Francisco I. Madero, y todos los sucesos que pasaron por aquellos años, Pearson tomó la decisión de vender las acciones del Ferrocarril del Istmo al gobierno de Venustiano Carranza, con lo que a partir del 19 de enero de 1918 todo lo relacionado con el ferrocarril quedó en manos del gobierno federal.

\section{()(1) $(3$}


se encontraban los verdaderos constructores de dicha vía. Esos hombres que con base en el trabajo aportaron el mayor esfuerzo para lograr el éxito.

Lo que hemos pretendido rescatar en este trabajo es la presencia de los trabajadores como parte fundamental en la construcción del Ferrocarril de Tehuantepec. Principalmente analizamos la huelga de 1903, no como un hecho aislado y único sino inserto en un mundo de conflictos laborales sucedidos en México desde 1880. En esa década tenemos el periodo de mayor crecimiento industrial, las huelgas de los trabajadores "eran a menudo actos desesperados". No obstante, en los años noventa se dio un cambio, no tanto en el actuar, sino en los motivos por los que se lanzaban a las huelgas, a saber, lo que vemos en esta década es un mayor descontento en la manera en que las empresas imponían las condiciones de trabajo, como era la jornada laboral, los bajos salarios, el trato que se le daba a los obreros, las regulaciones estrictas a las que eran sometidos, entre otras (Anderson, 2006, p. 115). Esas "condiciones" resultaban muchas veces estar acorde con las necesidades de la empresa, mas no con las del trabajador.

La huelga fue la acción más recurrida por los trabajadores, ya que les permitía manifestar de alguna manera su desacuerdo con el avance económico y político que empezaban a tomar el capitalismo. Eso explica también por qué las demandas laborales superaron las exigencias de las ocho horas laborales y mejores sueldos en busca de una mayor representación dentro de la empresa o beneficios colectivos en vez de individuales. Por ello es importante observar las huelgas antes de 1906, año de las "grandes huelgas", para poder observar cómo manifestaron su descontento ante el capital.

La huelga del Ferrocarril de Tehuantepec de 1903 fue una de las muchas que sucedieron alrededor del mundo, al menos en el periodo 1899-1903. Sabemos que en Estados Unidos, España e Inglaterra muchos de los trabajadores del ferrocarril hicieron huelgas para exigir mejoras laborales en lo colectivo y mayor representación dentro de las empresas, los resultados fueron distintos en cada uno de los casos; sin embargo, me interesa enfatizar que no sólo en México estaban las organizaciones de trabajadores en un momento de transición, sino también lo estaban en muchos países, sobre todo vemos movimientos que buscaban mejoras sociales frente al avance de la economía capitalista.

Por último, analizar los detalles de un caso hasta ahora ignorado aporta luces para que la historiografía sobre los trabajadores del ferrocarril se acerque más a contar una historia de abandono, pero también de lucha.

\section{()(1) $(9$}




\section{LISTA DE REFERENCIAS}

Anderson, R. (2006). Parias en su propia tierra. Los trabajadores industriales en México, 1906-1911. México: Colegio de San Luis Potosí (Colección Investigaciones).

Basurto, J. (1970). El proletariado industrial en México (1850-1930). México: Instituto de Investigaciones Sociales-UNAM.

Carregha, L. (2009). Rieles y trabajadores. El origen de un nuevo sector obrero en S.L.P. durante el Porfiriato. Mirada Ferroviaria, 7, 9-17.

Cérbulo Pérez, V. M. (coord.), Ballesteros Rojo, M., García Cortés, R., Portador García, T. de J., Ramírez Colmenares, E., Rueda Hernández, A. (2006). ¿No oyes pitar el tren? Un acercamiento a la historia y la cultura de Matías Romero Avendaño. Oaxaca: Conaculta/Estado de Oaxaca/Honorable Ayuntamiento de Matías Romero Avendaño.

Clark, M. (1979). La organización obrera en México. México: Ediciones Era (Problemas de México).

Garner, P. (2005). Sir Weetman Pearson y el desarrollo nacional de México, 1889 y 1920. Recuperado de http://www.historicas.unam.mx/moderna/ehmc/ehmc30/358.html

Guajardo, G. (2010). Trabajo y tecnología en los ferrocarriles de México: una visión histórica, 1850-1950. México: Conaculta (Colección El Centauro).

Leal, J. (1985). Agrupaciones y burocracia sindicales en México. México: Pinem/Terra Nova.

Leal, J. (1991). Del mutualismo al sindicalismo en México: 1843-1911. México: Ediciones El Caballito.

Lear, J. (1997). Del mutualismo a la resistencia: las organizaciones laborales en la ciudad de México desde fines del porfiriato a la revolución. En C. Illades y A. Rodríguez Kuri (eds.), Ciudad de México: instituciones, actores sociales y conflicto político, 1774-1931. México: UAM/El Colegio de Michoacán.

Rodea, M. N. (1944). Historia del movimiento obrero ferrocarrilero en México (1890-1943). México: Exlibris/M. Rodea.

Rojas, A. (1995). La huelga de maquinistas y fogoneros del ferrocarril nacional de Tehuantepec. Boletín del Archivo General de la Nación, 4.

Rojas, A. (1996). Reconstrucción del Ferrocarril Nacional de Tehuantepec, 1894-1919 (Tesis de maestría inédita). Universidad Autónoma Metropolitana-Iztapalapa, México.

Rojas, A. (2004). El Ferrocarril de Tehuantepec, ¿El eje del comercio del mundo? 1893-1993 (Tesis de doctorado inédita). UAM-I, México.

Shabot, E. (1982). Los orígenes del sindicalismo ferrocarrilero. México: Ediciones El Caballito.

\section{()(1) $\$$}


Saraiba, M. (2005). El impacto de la modernidad en el istmo veracruzano a principios del siglo xx. Recuperado de http://cdigital.uv.mx/bitstream/123456789/8850/1/sotav11-Pag93-114.pdf

Sedano, M. (2012). "Ansia para hacer su Agosto": El Ferrocarril de Tehuantepec y la sociedad del Istmo (1899-1911) (Tesis de licenciatura inédita). UNAM, México.

Woldenberg, J. (1980). La huelga de la Unión de Mecánicos Mexicanos (1912-1913). Cuadernos del Centro de Estudios Políticos, 4.

Yanes Rizo, E. (1991). Vida y muerte de Fidelita, la novia de Acámbaro. Una historia social de la tecnología en los años cuarenta: el caso de los Ferrocarriles Nacionales de México. México: Conaculta (Regiones).

\section{OTRAS FUENTES}

Archivo

AGN Archivo General de la Nación.

\section{Bibliografía}

Rojas, A. (2005). Transporte ferroviario en el Istmo de Tehuantepec, 1896-1913. Recuperado de http://www.economia.unam.mx/amhe/memoria/simposio13/Armando\%20 ROJAS\%20ROSALES.pdf

Saraiba, M. (2000). Proceso modernizador en el istmo veracruzano 1900-1921. (Tesis de maestría inédita). UNAM, México.

Woldenberg, J. (1983). Antecedentes del sindicalismo. México: SEP/FCE. 